\title{
Health-related quality of life after coronary artery bypass grafting: A gender analysis using the Duke Activity Status Index
}

Colleen Gorman Koch, MD, MS

Farah Khandwala, $\mathrm{MS}^{\mathrm{b}}$

Jacek B. Cywinski, MD ${ }^{\mathrm{c}}$

Hemant Ishwaran, $\mathrm{PhD}^{\mathrm{b}}$

Fawzy G. Estafanous, MD ${ }^{c}$

Floyd D. Loop, MD ${ }^{\mathrm{d}}$

Eugene H. Blackstone, $M D^{b, d}$

Further appendixes are available online.
From the Departments of Cardiothoracic Anesthesia (G-3), ${ }^{\mathrm{a}}$ Biostatistics, ${ }^{\mathrm{b}}$ General Anesthesiology, ${ }^{\mathrm{c}}$ and Thoracic and Cardiovascular Surgery, ${ }^{\mathrm{d}}$ The Cleveland Clinic Foundation, Cleveland, Ohio.

Received for publication Sept 12, 2003; revisions requested Dec 2, 2003; accepted for publication Dec 12, 2003.

Address for reprints: Colleen Gorman Koch, MD, MS, Department of Cardiothoracic Anesthesia (G-3), The Cleveland Clinic Foundation, 9500 Euclid Ave, Cleveland, OH 44195 (E-mail: kochc@ ccf.org).

J Thorac Cardiovasc Surg 2004;128:284-95 $0022-5223 / \$ 30.00$

Copyright $(9) 2003$ by The American Association for Thoracic Surgery

doi:10.1016/j.jtcvs.2003.12.033
Objective: Our objectives were to document the preoperative and postoperative functional status of patients undergoing coronary artery bypass grafting, to examine factors that influence functional recovery, and to determine whether gender differences exist in the preoperative and postoperative functional status with the Duke Activity Status Index.

Methods: One thousand eight hundred twenty-five patients undergoing isolated coronary artery bypass grafting had baseline and follow-up quality-of-life surveys. Mean follow-up from baseline to postoperative Duke Activity Status Index was 8.0 months for women and men. The influence of 47 variables, in addition to baseline scores on postoperative functional status, was examined with logistic ordinal modeling. An ordinal model for the follow-up score was determined by means of backward selection, with variables retained if they satisfied the criterion of a $P$ value of less than .05 .

Results: Median baseline Duke Activity Status Index scores (women, 21.5; men, $32.2 ; P<.001$ ) and first follow-up scores (women, 42.7; men, 58.2; $P<.001$ ) were lower in women than in men. Patients who were older and those who had chronic obstructive pulmonary disease, myocardial infarction, stroke, diabetes, vascular disease, postoperative serious infection, and return to the operating room had lower postoperative scores. After adjusting for these factors, women still had lower follow-up scores (odds ratio for men, 2.1 [95\% confidence interval, 1.7-2.6]; $P<$ $.001)$.

Conclusions: A number of preoperative factors, operative variables, and postoperative events are associated with functional recovery after coronary revascularization. In addition, female gender is associated with more postoperative functional impairment after adjusting for these perioperative variables.

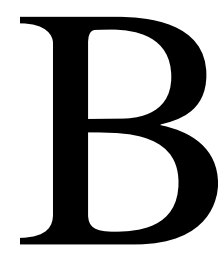

eyond the survival benefit of coronary artery bypass grafting ( $\mathrm{CABG})$, functional recovery is the expectation of patients who select CABG for relief of symptoms. Although there is general appreciation that $\mathrm{CABG}$ reduces or relieves angina, there is less appreciation that patient quality of life is improved after surgical intervention. ${ }^{1}$ Our objectives were to measure preoperative and postoperative functional status in patients undergoing isolated $\mathrm{CABG}$, identify factors influencing functional recovery, and determine whether there were gender differences in preoperative and postoperative functional status. To meet these 


\section{BOX 1. The Duke Activity Status Index}

\begin{tabular}{lc}
\hline \multicolumn{1}{c}{ Activity: Can You... } & Weight \\
\hline 1. take care of yourself, that is, eating dressing, & 2.75 \\
bathing or using the toilet? & 1.75 \\
2. walk indoor, such as around your house? & 2.75 \\
3. walk a block or 2 on level ground? & 5.50 \\
4. climb a flight of stairs or walk up a hill? & 8.00 \\
5. run a short distance? & 2.70 \\
6. do light work around the house like dusting \\
or washing dishes? \\
7. do moderate work around the house like \\
$\quad$ vacuuming, sweeping floors, or carrying in \\
groceries?
\end{tabular}

The Duke Activity Status Index score is the sum of positive responses.

objectives, physical aspects of quality of life were assessed with the Duke Activity Status Index (DASI; Box 1). ${ }^{2}$

\section{Methods}

\section{Patients}

Of the 3352 consecutive patients who underwent isolated CABG at the Cleveland Clinic Foundation from January 1, 1997, through December 31, 1998, 1825 completed both a baseline DASI survey and at least one postoperative DASI survey. The baseline DASI survey was given as a self-administered questionnaire to patients preoperatively. If a patient was unable to complete the questionnaire, a research assistant administered the survey by reading the exact wording of the survey questions. Patients completed the postoperative DASI survey by means of telephone interview at 6 and 12 months postoperatively. Among those patients who did not have a follow-up DASI survey, 39 died in hospital, and 18 died within 6 months after surgical intervention. There were small differences between responders and nonresponders that are detailed in Electronic Appendix 1. Baseline characteristics of the study population are listed in Appendixes 1 and 2, and postoperative morbidities are listed in Appendix 3.

\section{Duke Activity Status Index}

The DASI is a disease-specific quality-of-life questionnaire validated for cardiovascular disease. ${ }^{2,3}$ It is a self-administered 12item instrument that measures major activities of daily living, such as personal care, ambulation, household tasks, sexual function, and recreational activities (Box 1). ${ }^{2}$ Each item is weighted on the known metabolic cost of each activity, and weights of positive terms are summed to form the DASI score for the patient. ${ }^{2}$ The DASI is measured on a semicontinuous scale that allows for possible scores between 0 and 58.2. High scores represent better physical functioning, and a score of zero reflects inability to perform any basic activities of daily living. ${ }^{2}$

\section{Data}

Values for perioperative variables were prospectively collected concurrently with patient care by dedicated individuals trained in database management and entered into the Cleveland Clinic Foundation Department of Cardiothoracic Anesthesia Database. Institutional review board approval was obtained to perform research analyses on the database.

\section{Statistical Analyses}

Forty-seven variables were considered in the analysis, including baseline demographics, clinical history, laboratory values, operative variables, and postoperative morbid events.

Preliminary analysis. Before modeling, summary statistics for each variable were calculated. Approximately $6 \%$ of the patients had missing values for albumin and bilirubin. Noninformative imputation was used to supplement the data. Univariable statistics were initially computed to compare men and women by using the Student $t$ test for continuous variables and the $\chi^{2}$ or Fisher exact statistics for categoric variables. Also, because logistic ordinal regression would be used, the cumulative logit of grouped followup scores was plotted against continuous and ordinal variables to identify possible transformations necessary to linearize the relationship and to check for obvious violations of the proportional odds assumption.

Postoperative DASI surveys were collected at approximately 6 and 12 months (actual follow-up times ranged from 6-15 months). Of the 1825 patients, only 1138 completed surveys at both followup times. Although a longitudinal analysis was considered to study the change in scores over time, preliminary inspection of the change scores exhibited a notable similarity of scores at both follow-up times, with $64 \%$ of patients indicating no change. In addition, it has been reported that postoperative functional recovery status stabilizes by 6 months. ${ }^{4}$ To maximize the sample size, we therefore used the first observed postoperative DASI score as our primary end point and considered time to first follow-up as a fixed effect in the analysis. Mean intervals from baseline to first observed follow-up DASI were similar for women and men $(8.0 \pm$ 1.0 months for women vs $8.0 \pm 1.1$ months for men, $P=.89$ ).

Modeling. To perform an ordinal analysis, the scores were rounded to their lowest integer value and modeled against a list of explanatory variables, including baseline values, discretized into 10-point intervals (personal communication, Dr Eugene H. Blackstone). ${ }^{5}$ Ordinal regression produces an intercept estimate for each successive level of the response. Similar intercept estimates were grouped to establish an ordinal scale for the score, resulting in grouped scores of 0 to 18,19 to 26,27 to 32,33 to 42,43 to 50 , and 51 to 58. Finally, a model for the follow-up score was determined by means of backward selection, with a criterion of a $P$ value of less than .05 required for retention. The $\chi^{2}$ score test for the proportional odds assumption was met for the final model $(P=$ .18). None of the interaction terms investigated was statistically significant. 
Men and women were propensity matched on the basis of all preoperative and operative variables, postoperative morbidities, and baseline DASI scores to more simply compare the influence of gender on follow-up DASI scores with fewer assumptions (Electronic Appendix 2). ${ }^{6-9}$

All results were computed by using SAS 8.2 software (SAS Institute, Cary, NC).

\section{Results}

\section{Unadjusted Functional Recovery}

Median baseline DASI scores for the 483 women and 1342 men were 21.5 (25th percentile, $15.2 ; 75$ th percentile, 32.2 ) and 32.2 (25th percentile, 19.0; 75th percentile, 50.2; $P<$ .001 ), respectively. Figure $1, A$ displays the distribution of baseline scores by gender. Women dominated the lower DASI scores, whereas men more frequently had scores of greater than 51. Postoperative median scores for the first follow-up DASI survey for women and men were 42.7 (25th percentile, 30.2; 75th percentile, 58.2) and 58.2 (25th percentile, 42.7; 75th percentile, 58.2; $P<.001$ ), respectively (Figure $1, B$ ). Compared with the large spread of values preoperatively, where more than $10 \%$ of men and $3.5 \%$ of women had scores ranging between 51 and 58, the majority of patients had excellent functional recovery, with $56.7 \%$ of men and $31.7 \%$ of women having follow-up DASI scores of 51 to 58.

\section{Factors Associated with Functional Recovery}

Results from the ordinal regression model demonstrated that male gender was associated with higher follow-up DASI scores compared with female gender. Men were twice as likely than women to score in the highest functional follow-up DASI category compared with the other ordered categories (Table 1). Baseline DASI scores strongly influenced the postoperative DASI scores after adjusting for a number of comorbid conditions. For example, patients with baseline DASI scores of 50 or greater were more than twice as likely to have follow-up DASI scores in the high categories than those patients in the reference baseline DASI group (odds ratio, 2.4 [95\% confidence interval, 1.6-3.4], $P$ $<.001$ ). Use of a left internal thoracic artery graft was associated with a $30 \%$ greater chance of having follow-up DASI scores in the higher versus lower score groups compared with results in patients with vein grafts.

Variables associated with lower (less favorable) follow-up DASI scores included advanced age, longer interval from the operation to the first follow-up DASI, chronic obstructive pulmonary disease, and other comorbidities. In particular, patients with diabetes were $35 \%$ less likely to have a follow-up score in the 51- to 58-point range versus the other ordered categories.

Figure 2 illustrates the effect of gender and increasing age on functional recovery after CABG in patients with a low-risk profile. The low-risk patient profile includes no history of prior myocardial infarction, stroke, chronic ob- structive pulmonary disease, diabetes, vascular disease, or mitral valve dysfunction; average bilirubin level of 0.7 $\mathrm{mg} / \mathrm{dL}$; blood urea nitrogen level of $20 \mathrm{mg} / \mathrm{dL}$; aortic clamp time of 75 minutes; use of a left internal thoracic artery graft; no serious postoperative infection; or return to the operating room postoperatively. Average follow-up time for the low-risk patient profile is 8.0 months. As shown in Figure 2, the older patient will be less likely to be in the highest functional category and more likely to be in the lower functional categories. However, at all ages, women demonstrate lower probability of achieving follow-up scores in the 51- to 58-point range compared with men. Figure 3 displays the overall predicted probability of follow-up DASI score groups by age for low-risk women and men. Figure 4 shows the relationship of baseline DASI score, gender, and age to achieving a follow-up score of between 51 and 58 for patients with a low-risk profile. Women again demonstrate lower predicted probability of achieving scores in the 51- to 58-point category compared with men.

\section{Propensity-matched Comparison of Functional Recovery}

Among propensity-matched pairs, women had consistently lower median follow-up DASI scores compared with men (see Electronic Appendix 2).

\section{Discussion}

Quality-of-life measures reflect the patient's perception of his or her burden of disease. ${ }^{10,11}$ Because patients are interested in not only survival and relief of angina but also resumption of their daily activities, ${ }^{12}$ a comprehensive assessment of these aspects of quality of life are important. A number of studies have reported improvements in both physical and mental functional health status after coronary revascularization procedures. ${ }^{10,13-16}$ Interestingly, qualityof-life measures reflect hard outcome measures, such as postoperative mortality ${ }^{10,17-19}$ and hospital length of stay. ${ }^{18}$

\section{Gender, CABG, and Quality of Life}

Principal findings. Studies of gender differences in health-related quality of life after $\mathrm{CABG}$ report variable results with regard to the influence of gender (Table 2). Our investigation demonstrated that baseline and follow-up DASI scores for women were significantly lower than those of men. After taking into consideration differences in baseline scores, preoperative demographics, comorbid conditions, operative factors, and postoperative morbidities, women continued to have significantly lower functional status after coronary revascularization than men. Among the strengths of this investigation are the inclusion of operative factors and postoperative morbid outcome events in the analysis for postoperative functional recovery and the use of propensity matching to demonstrate gender differences in 

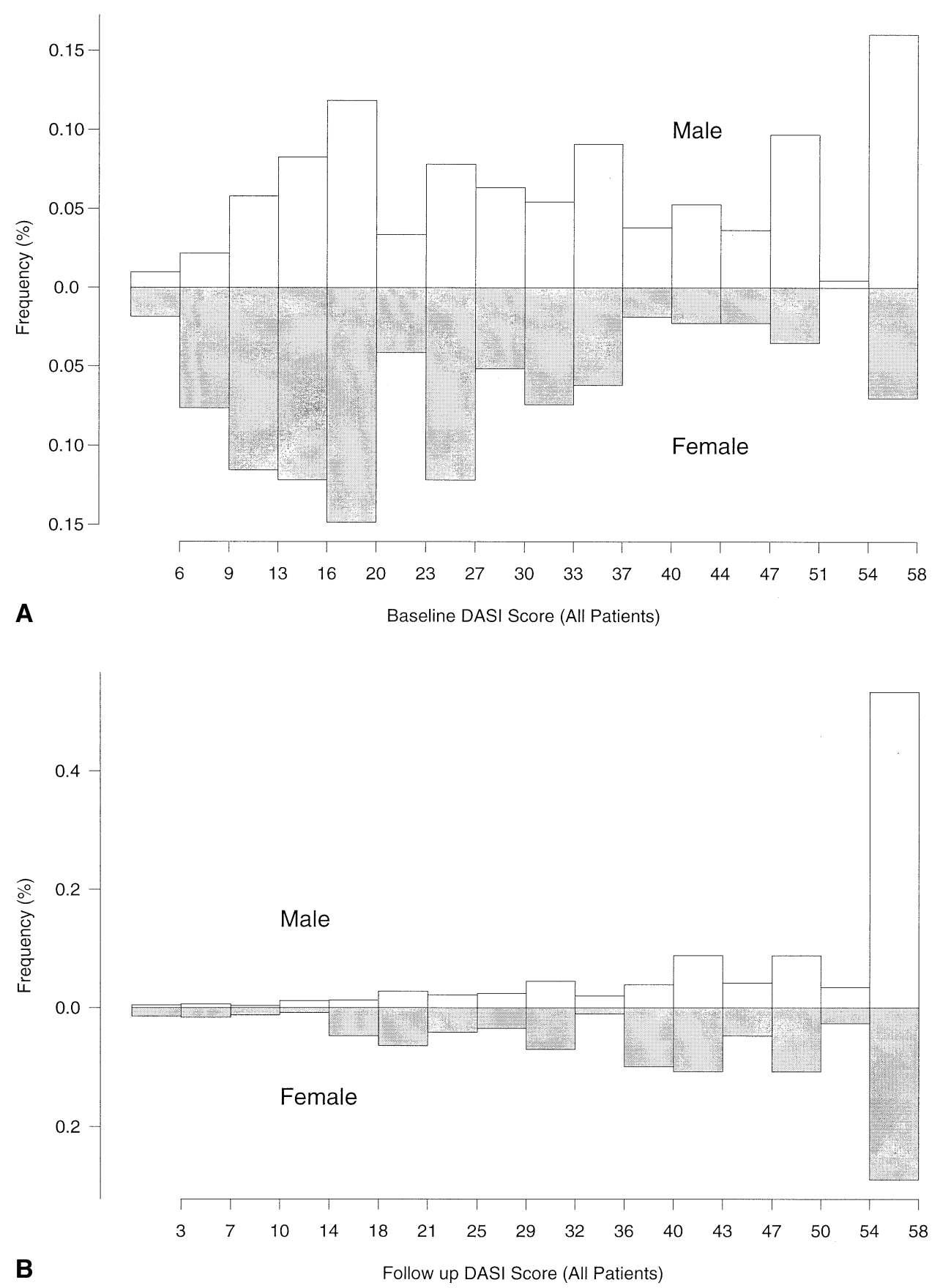

Figure 1. A, The gender distributions of baseline DASI scores are represented in this mirrored histogram. Men have a greater frequency of scoring in the highest functional score group compared with women. B, Follow-up DASI scores are displayed in this mirrored histogram. Women continue to have a lower frequency of representation in the highest functional group compared with men.

postoperative functional recovery. A number of other perioperative factors significantly affected postoperative functional recovery for both women and men in the months after CABG (Table 1).

Others have reported results consistent with our findings (see Table 2). Sjoland and colleagues ${ }^{14}$ prospectively ex- amined the effects of CABG on quality of life and exercise capacity. They reported improvement in patients' quality of life 2 years after CABG with all 3 quality-of-life instruments used in their investigation. In addition, those patients with the most impaired exercise capacity, those with the most severe angina, and women appeared to have the great- 
TABLE 1. Factors associated with follow-up DASI scores (multivariable ordinal logistic regression)

\begin{tabular}{|c|c|c|c|}
\hline Factor & Estimate $\pm S E$ & $\begin{array}{l}\text { Estimated odds ratio } \\
\text { (95\% confidence interval) }\end{array}$ & $P$ value \\
\hline $\begin{array}{l}\text { Baseline DASI score* } \\
10-20 \\
20-30 \\
30-40 \\
40-50 \\
50-60\end{array}$ & $\begin{array}{l}0.60 \pm 0.17 \\
0.61 \pm 0.18 \\
0.84 \pm 0.18 \\
0.98 \pm 0.22 \\
0.87 \pm 0.19\end{array}$ & $\begin{array}{l}1.8(1.3-2.5) \\
1.8(1.3-2.6) \\
2.3(1.6-3.3) \\
2.7(1.7-4.1) \\
2.4(1.6-3.4)\end{array}$ & $<.001$ \\
\hline $\begin{array}{l}\text { Higher (better score) } \\
\text { Demography }\end{array}$ & $075+0.11$ & 2117261 & -001 \\
\hline $\begin{array}{l}\text { Male } \\
\text { Laboratory } \\
\text { Bilirubin } \\
\text { Operative }\end{array}$ & $\begin{array}{l}0.75 \pm 0.11 \\
0.30 \pm 0.14\end{array}$ & $\begin{array}{l}2.1(1.7-2.6) \\
1.4(1.0-1.78)\end{array}$ & $\begin{array}{r}<.001 \\
.04\end{array}$ \\
\hline $\begin{array}{l}\text { Total aortic clamp time } \\
\text { Left internal thoracic artery used }\end{array}$ & $\begin{array}{c}0.0043 \pm 0.0015 \\
0.24 \pm 0.11\end{array}$ & $\begin{array}{l}1.0(1.0-1.0) \\
1.3(1.0-1.6)\end{array}$ & $\begin{array}{l}.004 \\
.03\end{array}$ \\
\hline $\begin{array}{l}\text { Lower (worse score) } \\
\text { Demography }\end{array}$ & & & \\
\hline $\begin{array}{l}\text { Age } \\
\text { Laboratory } \\
\text { BUN }\end{array}$ & $\begin{array}{l}-0.028 \pm 0.0052 \\
-0.010 \pm 0.0050\end{array}$ & $\begin{array}{l}0.97(0.96-0.98) \\
0.99(0.98-1.0)\end{array}$ & $\begin{array}{r}<.001 \\
.04\end{array}$ \\
\hline $\begin{array}{l}\text { Cardiac comorbidity } \\
\text { History of myocardial infarction } \\
\text { Mitral valve regurgitation }\end{array}$ & $\begin{array}{l}-0.23 \pm 0.093 \\
-0.32 \pm 0.13\end{array}$ & $\begin{array}{l}0.80(0.66-0.95) \\
0.73(0.6-0.95)\end{array}$ & $\begin{array}{l}.01 \\
.02\end{array}$ \\
\hline $\begin{array}{l}\text { Noncardiac comorbidity } \\
\text { History of chronic obstructive pulmonary disease } \\
\text { History of stroke } \\
\text { History of diabetes } \\
\text { History of vascular disease }\end{array}$ & $\begin{array}{l}-0.58 \pm 0.18 \\
-0.73 \pm 0.18 \\
-0.42 \pm 0.10 \\
-0.33 \pm 0.14\end{array}$ & $\begin{array}{l}0.56(0.40-0.79) \\
0.48(0.34-0.68) \\
0.65(0.54-0.79) \\
0.72(0.6-0.94)\end{array}$ & $\begin{array}{r}.008 \\
<.001 \\
<.001 \\
.014\end{array}$ \\
\hline $\begin{array}{l}\text { Postoperative morbidity } \\
\quad \text { Serious infection morbidity } \\
\text { Return to operating room } \\
\text { Follow-up time }\end{array}$ & $\begin{array}{r}-1.2 \pm 0.39 \\
-0.41 \pm 0.20 \\
-0.16 \pm 0.04\end{array}$ & $\begin{array}{l}0.31(0.15-0.66) \\
0.66(0.4-0.98) \\
0.85(0.8-0.93)\end{array}$ & $\begin{array}{c}.002 \\
.04 \\
<.001\end{array}$ \\
\hline $\begin{array}{l}\text { Intercepts } \\
\text { Follow-up score } 51-58 \dagger \\
\text { Follow-up score } 43-50 \dagger \\
\text { Follow-up score } 33-42 \dagger \\
\text { Follow-up score } 27-32 \dagger \\
\text { Follow-up score } 19-26 \dagger\end{array}$ & $\begin{array}{l}1.8 \pm 0.55 \\
2.4 \pm 0.55 \\
3.4 \pm 0.56 \\
3.9 \pm 0.56 \\
4.6 \pm 0.56\end{array}$ & & $\begin{array}{r}\quad .001 \\
<.001 \\
<.001 \\
<.001 \\
<.001\end{array}$ \\
\hline
\end{tabular}

$D A S I$, Duke Activity Status Index; BUN, blood urea nitrogen.

*The reference group for the baseline DASI scores is 0 to 10 .

tIntercept term representing the cumulative increase in follow-up scores.

est improvements in quality of life after CABG. However, patients, such as women, who start at low baseline scores have more opportunity for improvement. Furthermore, despite greater absolute improvement for women in their investigation, the Nottingham Health Profile scores and exercise capacity were significantly less favorable for women preoperatively and postoperatively compared with those for men.

In a recent investigation, Vaccarino and associates ${ }^{20}$ examined the influence of gender on recovery in the 4- to 6-week recovery period after CABG. Women had lower baseline Short Form-36 physical functioning scores, as well as more preoperative unstable angina and heart failure.
Adjusted results demonstrated higher hospital readmission rates for women, a decrease in physical functioning from baseline, and worsening depressive symptoms. Male patients' physical functioning remained unchanged, and their depressive symptoms improved. After stratifying patients according to baseline scores, they reported that women had significantly lower physical functioning scores than men at follow-up for each quintile of baseline physical functioning scores. Stratification also demonstrated that women in all groups except the lowest category of preoperative physical functioning demonstrated a decrease in functional status in the 6- to 8-week follow-up period compared with men, who reported slight improvements. Although we also reported 


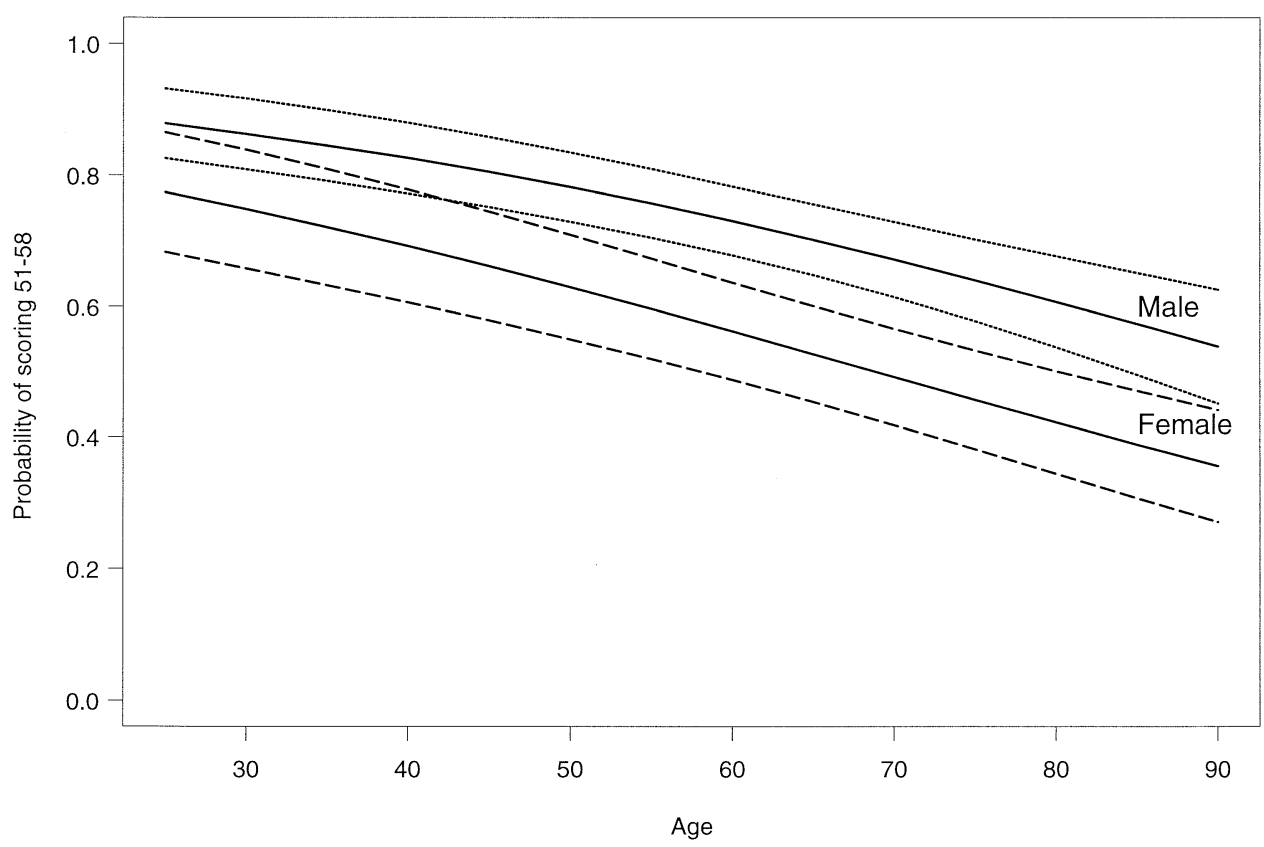

Figure 2. The predicted probability of follow-up DASI scores by age and sex for patients with a low-risk profile are displayed in this graph. Male patients have an overall higher probability of scoring in the highest follow-up DASI group (51-58) compared with women for each of the age groupings. The dotted and dashed lines represent 95\% confidence intervals for men and women, respectively.

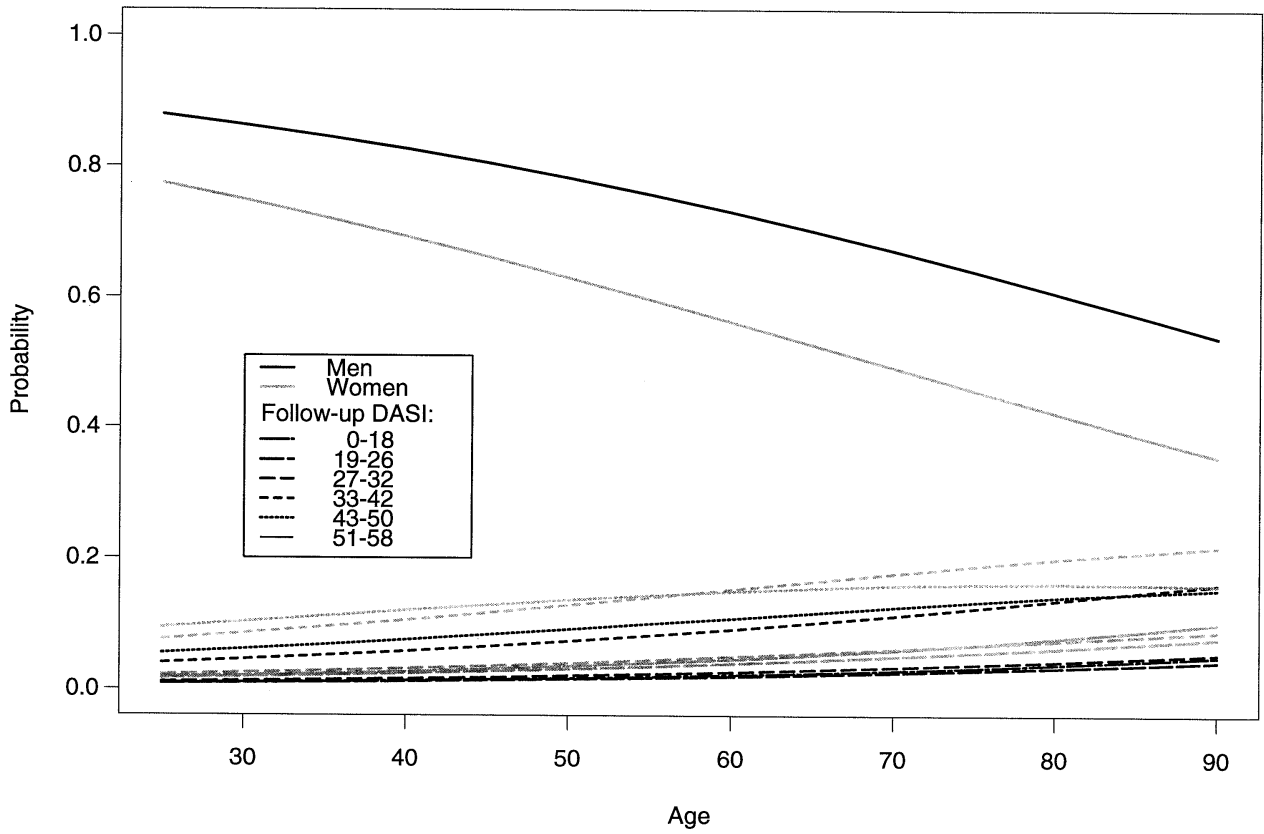

Figure 3. The overall predicted probability of male and female patients scoring in each of the follow-up DASI score groups by age is displayed in this graph. Note that within each age grouping, women consistently have a lower probability of scoring in the 51- to 58-point follow-up group compared with men.

lower baseline and follow-up scores for women compared with men, women had a relative improvement in functional recovery after $\mathrm{CABG}$ in contrast to a decrease, as demonstrated by Vaccarino and associates. Differences in study results might be more reflective of the timing for follow-up quality-of-life measures. Vaccarino and associates performed their follow-up between 6 and 8 weeks postoperatively, whereas our follow-up was 6 to 12 months postoperatively. 


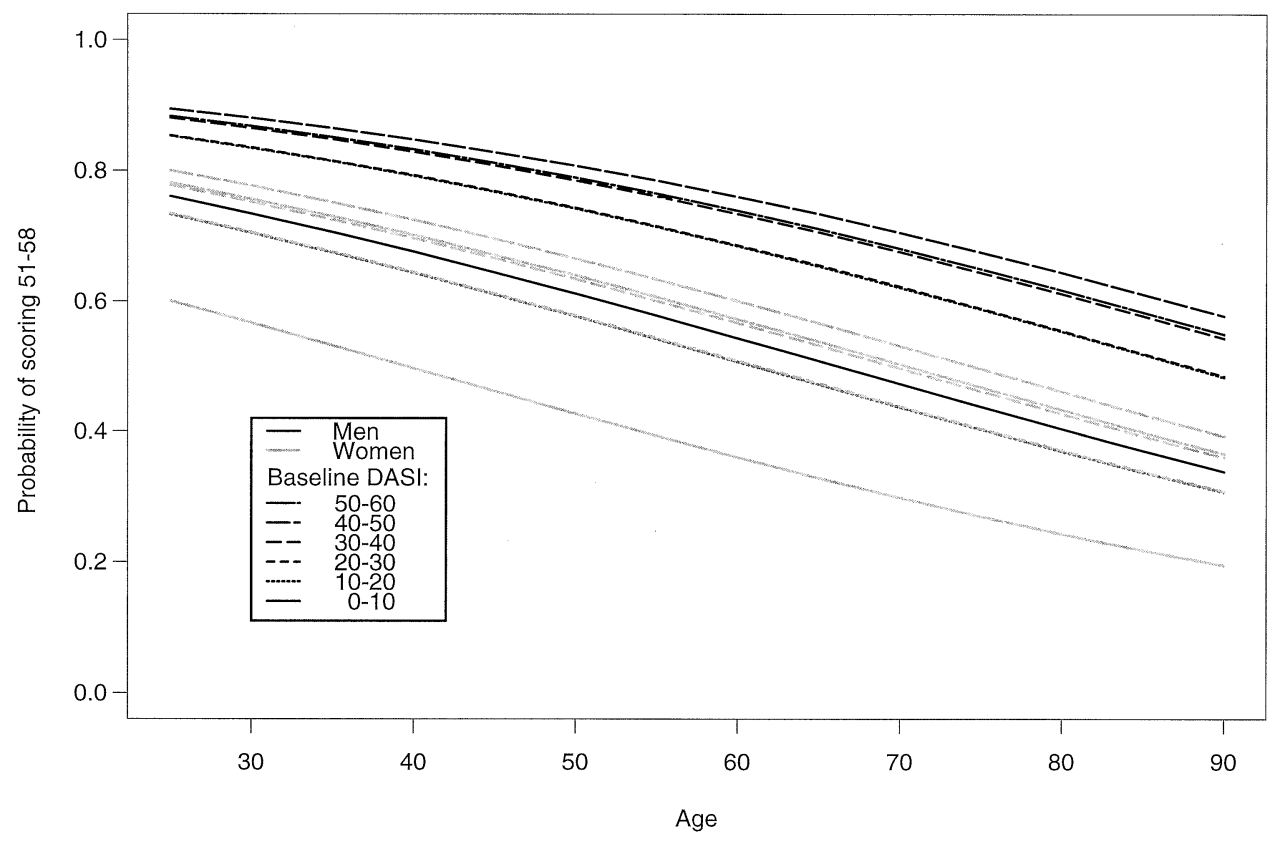

Figure 4. The predicted probability of low-risk patients scoring between 51 and 58 on follow-up DASI by age and baseline scores is represented in this graph. For each of the baseline DASI groups, female patients have an overall lower probability of scoring in the 51- to 58-point follow-up DASI group compared with men.

Herlitz and coworkers ${ }^{12}$ identified female sex as an independent predictor for inferior quality of life after CABG. A history of diabetes and chronic obstructive pulmonary disease were also associated with poor quality of life. Multivariable analysis showed that a poor preoperative quality of life was a strong predictor for an impaired quality of life 5 years after $\mathrm{CABG}$. This investigation dichotomized the 3 quality-of-life scores by defining an inferior quality of life as worse than the median value for the 3 individual instruments.

Artinian and Duggan ${ }^{21}$ examined sex differences in physical, psychologic, and social recovery after CABG. They reported a slower physical recovery for women than men during the 6-week period after discharge. Although both women and men experienced continuous improvement over time with physical aspects of recovery, men experienced significantly quicker improvement. No adjustments were made to control for the differences in preoperative risk profiles between the women and men or the effect of the different risk profiles on functional recovery.

A number of investigations similarly report less satisfactory health status for women compared with men after coronary revascularization. ${ }^{16,22,23}$

Other studies have reported similar quality-of-life outcomes after coronary revascularization in women and men. Ayanian and colleagues ${ }^{24}$ assessed the physical and psychosocial functional status in patients undergoing CABG. Although women presented as more "severely ill" than men preoperatively, they reported similar physical and psychosocial functioning after surgical intervention. Unadjusted postoperative scores for instrumental activities of daily living and vitality were significantly lower for women compared with for men; however, after adjustment for age, marital status, education, severity of angina, recent myocardial infarction, congestive heart failure, and preoperative coexisting illnesses, the differences became insignificant. Women reported adjusted gains that were similar to or greater than those of men in instrumental activities of daily living and vitality.

Stewart and associates ${ }^{25}$ also found similar functional outcomes for women and men after CABG. Women had lower preoperative and follow-up DASI scores; however, in the multivariable regression analyses female gender was not an independent predictor of mean change in DASI score or a predictor of postoperative functional recovery.

Our findings that baseline DASI scores have a significant effect on postoperative DASI scores are consistent with the findings of other publications. ${ }^{12,15,23}$ Rumsfeld and coworkers ${ }^{15}$ examined the relationship between preoperative health status and changes in quality of life after CABG. On average, patients' Mental Component Summary and Physical Component Summary scores improved in the 6-month followup period. Preoperative health status was the major determinant of change in quality of life after adjusting for anginal burden and other clinical characteristics. They found that patients with good preoperative health status were more likely to have a decrease in their postoperative health- 
TABLE 2. Quality-of-life studies

\begin{tabular}{|c|c|c|c|c|c|c|c|}
\hline Data source & $\begin{array}{l}\text { Sample } \\
\text { size }\end{array}$ & $\begin{array}{l}\text { Quality-of-life } \\
\text { instrument }\end{array}$ & Validated? & Baseline & Follow-up & Analysis & Findings \\
\hline $\begin{array}{l}\text { Ayanian et } \\
\mathrm{al}^{24}\end{array}$ & $\begin{array}{l}W=66 \\
M=240\end{array}$ & $\begin{array}{l}\text { FSO, SF-36 } \\
\text { vitality scale }\end{array}$ & Yes & 6 mo postop & $6 \mathrm{mo}$ & $\begin{array}{l}\text { ANCOVA, logistic } \\
\text { regression }\end{array}$ & $\begin{array}{l}\text { Similar physical and } \\
\text { psychosocial } \\
\text { functioning for } \\
\text { women and men }\end{array}$ \\
\hline Stewart et $\mathrm{al}^{25}$ & $\begin{array}{l}W=54 \\
M=104\end{array}$ & DASI & Yes & $\begin{array}{l}50 \% \text { preop } \\
50 \% \text { postop before } \\
\quad \text { discharge }\end{array}$ & $6 \mathrm{mo}$ & $\begin{array}{l}\text { Linear and } \\
\text { logistic } \\
\text { regression }\end{array}$ & $\begin{array}{l}\text { Similar functional } \\
\text { improvement for } \\
\text { women and men }\end{array}$ \\
\hline Sjoland et $\mathrm{al}^{27}$ & $\begin{array}{l}W=196 \\
M=964\end{array}$ & $\begin{array}{l}\text { PGWB, NHP, } \\
\text { PAS }\end{array}$ & Yes & Preop & $3,12,24 \mathrm{mo}$ & $\begin{array}{l}\text { Mann-Whitney } U \\
\text { test, chi- } \\
\text { square test, } \\
\text { Cochran- } \\
\text { Mantel- } \\
\text { Haenszel, } \\
\text { Wilcoxon } \\
\text { signed rank } \\
\text { and sign test }\end{array}$ & $\begin{array}{l}\text { Quality-of-life } \\
\text { scores less } \\
\text { favorable for } \\
\text { women }\end{array}$ \\
\hline Sjoland et al ${ }^{14}$ & $\begin{array}{l}\text { NHP: } \\
\qquad \begin{array}{l}\text { W }=184 \\
M=911\end{array} \\
\text { Exercise test: } \\
\quad W=48 \\
M=313\end{array}$ & $\begin{array}{l}\text { PGWB, NHP, } \\
\text { PAS }\end{array}$ & Yes & Preop & $24 \mathrm{mo}$ & $\begin{array}{l}\text { Wilcoxon signed } \\
\text { rank test, } \\
\text { Spearman } \\
\text { rank order } \\
\text { correlation }\end{array}$ & $\begin{array}{l}\text { Quality-of-life } \\
\text { scores and } \\
\text { exercise capacity } \\
\text { less favorable for } \\
\text { women }\end{array}$ \\
\hline $\begin{array}{l}\text { Vaccarino et } \\
\qquad \mathrm{al}^{20}\end{array}$ & $\begin{array}{l}W=309 \\
M=804\end{array}$ & $\begin{array}{l}\text { SF-36 (PF), } \\
\text { GDS, ESSI }\end{array}$ & Yes & $\begin{array}{c}\text { Postop before } \\
\text { discharge }\end{array}$ & $6-8 w k$ & $\begin{array}{l}\text { ANCOVA, logistic } \\
\text { regression }\end{array}$ & $\begin{array}{l}\text { Women have less } \\
\text { favorable PF, } \\
\text { worse depressive } \\
\text { symptoms }\end{array}$ \\
\hline Carey et $\mathrm{al}^{26}$ & $\begin{array}{l}W=287 \\
M=1048\end{array}$ & Questionnaire & No & 6 mo postop & $\begin{array}{l}12 \text { mo, } \\
\text { annually } \\
\text { for } 2-18 \text { y } \\
\text { (mean } \\
\text { 4.3) }\end{array}$ & $\begin{array}{l}\text { ANOVA, } \\
\text { Wilcoxon } \\
\text { rank-sum, chi- } \\
\text { square }\end{array}$ & $\begin{array}{l}\text { Mean health status } \\
\text { less favorable for } \\
\text { women }\end{array}$ \\
\hline Yun et $\mathrm{al}^{22}$ & $\begin{array}{l}W=162 \\
M=381\end{array}$ & HSO & Yes & Preop & $\begin{array}{c}3,12 \text {, and } \\
24 \mathrm{mo}\end{array}$ & $\begin{array}{l}\text { Repeated- } \\
\text { measures } \\
\text { ANOVA, } \\
\text { multivariable } \\
\text { regression }\end{array}$ & $\begin{array}{l}\text { Lower scores for } \\
\text { women in a } \\
\text { majority of } \\
\text { quality-of-life } \\
\text { measures }\end{array}$ \\
\hline Artinian et $\mathrm{al}^{21}$ & $\begin{array}{l}W=47 \\
M=132\end{array}$ & $\begin{array}{c}\text { SIP, SI, BDI, } \\
\text { RSS, CLS }\end{array}$ & Yes & $\begin{array}{c}\text { Postop before } \\
\text { discharge }\end{array}$ & $\begin{array}{l}1,3 \text {, and } 6 \\
\text { wk }\end{array}$ & $\begin{array}{l}\text { Repeated- } \\
\text { measures } \\
\text { ANOVA }\end{array}$ & $\begin{array}{l}\text { Women have } \\
\text { slower recovery, } \\
\text { less physical } \\
\text { functioning }\end{array}$ \\
\hline Herlitz et al ${ }^{12}$ & $\begin{array}{l}W=142 \\
M=771\end{array}$ & $\begin{array}{l}\text { PAS, PGWI, } \\
\text { NHP }\end{array}$ & Yes & Preop & $5 y$ & $\begin{array}{l}\text { Logistic } \\
\quad \text { regression }\end{array}$ & $\begin{array}{l}\text { Poorer quality of life } \\
\text { for women }\end{array}$ \\
\hline Mayer et $\mathrm{al}^{23}$ & $\begin{array}{l}W=39 \\
M=84\end{array}$ & SF-36 & Yes & 1-1.5 y postop & $1-1.5 y$ & $\begin{array}{l}\text { Student } t \text {, chi- } \\
\text { square test }\end{array}$ & $\begin{array}{l}\text { Poorer functional } \\
\text { status for women }\end{array}$ \\
\hline
\end{tabular}

FSO, Functional Status Questionnaire; SF-36, Medical Outcomes Trust Short Form 36-item Health Survey; ANCOVA, analysis of covariance; ANOVA, analysis of variance; DASI, Duke Activity Status Index; PGWB, Psychological General Well-being Index; NHP, Nottingham Health Profile; PAS, Physical Activity Score; $P F$, physical function subscale; GDS, Geriatric Depression Scale; ESSI, Social Support Inventory of Enhancing Recovery In Coronary Heart Disease (ENRICH); HSQ, Health Status Questionnaire; SIP, Sickness Impact Profile; SI, Symptom Inventory; BDI, Beck Depression Inventory; RSS, Rosenberg Self-Esteem Scale; CLS, Cantril Ladder Scale.

related quality of life, leading them to recommend CABG only if it is predicted to improve survival. In contrast to Rumsfeld and colleagues' investigation, we demonstrated, with ordinal regression analysis, that patients with higher baseline DASI scores do not necessarily have a decrease in their functional capacity after CABG. In each of the baseline DASI groups in our study (compared with in the reference DASI group), patients were more likely to be repre- 
sented in the higher follow-up DASI score groups than the lower follow-up DASI score groups (odds ratio, 1.8-2.7).

Critique of the state of the art. A number of investigations have been limited by small sample size, ${ }^{21,22,24,25}$ retrospective collection of preoperative quality-of-life measures in the postoperative follow-up period, ${ }^{23,24}$ and use of quality-of-life measures that have not been validated. ${ }^{26}$ Furthermore, some did not consider the influence of operative factors or postoperative morbid outcome events on subsequent functional recovery. ${ }^{12,14,20-24,27}$ The variability in quality-of-life instruments used and the different follow-up intervals and statistical approaches to data analysis limits generalizability of the individual study results (see Table 2).

\section{Study Limitations}

Our investigation was done in a tertiary care center and therefore is limited in its ability to generalize results to practice in the community setting. The DASI assesses the physical component of health-related quality of life in patients with coronary disease. Quality of life after CABG encompasses multiple dimensions comprising both physical functioning and psychosocial factors. A number of investigations have reported a strong association between mental health status, such as depressive symptoms, and poor overall health status outcomes in patients with coronary artery disease. ${ }^{28-30}$

Although we included preoperative and operative variables, as well as postoperative morbid events, the lower preoperative and follow-up DASI scores for women in our study might reflect variables not collected. Consider that women might experience more ambulation difficulties unrelated to symptoms of coronary artery disease in which revascularization procedures would not improve women to the full functional capacity of men. As quality-of-life instruments become part of risk stratification for patients undergoing $\mathrm{CABG}$, parameters that assess ambulation impairment might need to be collected.

\section{Clinical Inferences}

Unfavorable patient characteristics, such as diabetes, obesity, hypertension, and increased triglycerides, typify the female patient undergoing CABG. ${ }^{31}$ Patients with an unfavorable risk profile who go on to have reduced postoperative functional capacity have the most to gain from cardiac rehabilitation programs. Studies have demonstrated that benefits of cardiac rehabilitation programs include improvement in long-term prognosis, reduced readmissions to the hospital, ${ }^{32}$ decrease in submaximal heart rate, ${ }^{33}$ and improvement in exertional capacity and cardiac function. ${ }^{34,35}$ Dylewicz and colleagues ${ }^{36}$ reported that short-term endurance training in patients after $\mathrm{CABG}$ resulted in a favorable modifying factor for glucose metabolism and an advanta- geous alteration of lipid metabolism parameters. They suggested that endurance training might be useful for the secondary prevention of coronary heart disease in patients who have undergone $\mathrm{CABG}$, especially in patients with abnormal carbohydrate and lipid metabolism results. Despite these potential gains from cardiac rehabilitation programs, such programs are underused by women. ${ }^{37,38}$

\section{Conclusions}

In our study of 1825 patients, women report more functional limitations after CABG than men. Women with reduced postoperative functional capability and a greater prevalence of modifiable risk factors could benefit from more aggressive referral to cardiac rehabilitation programs after CABG.

We thank Edward J. Mascha, MS, and Susana Arrigain, MA, from the Department of Biostatistics for performing preliminary analyses on this data set. We would also like to thank the physician assistants in the Department of Thoracic and Cardiovascular Surgery for assisting in the administration of the DASI instrument and the Department of Cardiothoracic Anesthesia Database team for entering the information into the database.

\section{References}

1. Hedeshian M, Namour N, Dziakik E, Stewart R, Campos C. Does increasing age have a negative impact on six-month functional outcome after coronary artery bypass? Surgery. 2002;132:239-44.

2. Hlatky M, Boineau R, Higginbotham M, Lee K, Mark D, Califf R, et al. A brief self-administered questionnaire to determine functional capacity (The Duke Activity Status Index). Am J Cardiol. 1989;64: 651-4.

3. Nelson C, Herndon J, Mark D, Pryor D, Califf R, Hlatky M. Relation of clinical and angiographic factors to functional capacity as measured by the Duke Activity Status Index. Am J Cardiol. 1991;68:973-5.

4. Barnason S, Zimmerman L, Anderson A, Mohr-Burt S, Nieveen J. Functional status outcomes of patients with a coronary artery bypass graft over time. Heart Lung. 2000;29:33-46.

5. Reference deleted on revision.

6. Rosenbaum P, Rubin D. The central role of the propensity score in observational studies for causal effects. Biometrika. 1983;70:41-55.

7. Drake C, Fisher L. Prognostic models and the propensity score. Int J Epidemiol. 1995;24:183-7.

8. Rosenbaum P, Rubin D. Reducing bias in observational studies using subclassification on the propensity score. J Am Stat Assoc. 1984;79: 516-24.

9. Blackstone EH. Comparing apples and oranges. J Thorac Cardiovasc Surg. 2002;123:8-15.

10. Pocock S, Henderson R, Seed P, Treasure T, Hampton J. Quality of life, employment status, and anginal symptoms after coronary angioplasty or bypass surgery. Circulation. 1996;94:135-42.

11. Rumsfeld J. Health status and clinical practice: when will they meet? Circulation. 2002;106:5-7.

12. Herlitz J, Wiklund I, Caidahl K, Karlson B, Sjoland H, Hartford M, et al. Determinants of an impaired quality of life five years after coronary artery bypass surgery. Heart. 1999;81:342-6.

13. Mayer C, Ergina P, Morin J, Gold S. Self-reported functional status as a predictor of coronary artery bypass graft surgery outcomes in elderly patients. Can J Cardiol. 2003;19:140-4.

14. Sjoland H, Wiklund I, Caidahl K, Haglid M, Westberg S, Herlitz J. Improvement in quality of life and exercise after coronary bypass surgery. Arch Intern Med. 1996;156:265-71.

15. Rumsfeld J, Magid D, O’Brien M, McCarthy M, MaWhinney S, Shroyer L, et al. Changes in health-related quality of life following 
coronary artery bypass graft surgery. Ann Thorac Surg. 2001;72:202632.

16. Welke K, Stevens J, Schults W, Nelson E, Beggs V, Nugent W. Patient characteristics can predict improvement in functional health after elective coronary artery bypass grafting. Ann Thorac Surg. 2003;75: 1849-55.

17. Rumsfeld J, MaWhinney S, McCarthy M, Shroyer A, VillaNueva C, O'Brien $\mathrm{M}$, et al. Heath-related quality of life as a predictor of mortality following coronary artery bypass graft surgery. JAMA. 1999; 281:1298-303.

18. Curtis L, Phelps C, McDermott M, Rubin H. The value of patientreported health status in predicting short-term outcomes after coronary artery bypass graft surgery. Med Care. 2002;40:1090-100.

19. Inouye S, Peduzzi P, Robison J, Hughes J, Horwitz R, Concato J. Importance of functional measures in predicting mortality among older hospitalized patients. JAMA. 1998;279:1187-93.

20. Vaccarino V, Lin Z, Kasl S, Mattera J, Roumanis S, Abramson J, et al. Gender differences in recovery after coronary artery bypass surgery. J Am Coll Cardiol. 2003;41:307-14.

21. Artinian N, Duggan C. Sex differences in patient recovery patterns after coronary artery bypass surgery. Heart Lung. 1995;24:483-94.

22. Yun K, Sintek C, Fletcher A, Pfeffer T, Kochamba G, Mahrer P, et al. Time related quality of life after elective cardiac operation. Ann Thorac Surg. 1999;68:1314-20.

23. Mayer C, Ergina P, Morin J, Gold S. Self-reported functional status as a predictor of coronary artery bypass graft surgery outcome in elderly patients. Can J Cardiol. 2003;19:140-4.

24. Ayanian J, Guadagnoli E, Cleary P. Physical and psychosocial functioning of women and men after coronary artery bypass surgery. JAMA. 1995;274:1767-70.

25. Stewart R, Blair J, Emond C, Lahey S, Levitsky S, Campos C. Gender and functional outcome after coronary artery bypass. Surgery. 1999; 126:184-90.

26. Carey J, Cukingnan R, Singer L. Health status after myocardial revascularization: inferior results in women. Ann Thorac Surg. 1995;59: 112-7.

27. Sjoland H, Wiklund I, Caidahl K, Hartford M, Karlsson T, Herlitz J. Improvement in quality of life differs between women and men after coronary artery bypass surgery. J Intern Med. 1999;245:445-54.
28. Pocock S. A perspective on the role of quality-of-life assessment in clinical trials. Control Clin Trials. 1991;12(suppl):257S-65S.

29. Rumsfeld J, Magid D, Plomondon M, O’Brien M, Spertus J, Every N, et al. Predictors of quality of life following acute coronary syndromes. Am J Cardiol. 2001;88:781-4.

30. Barefoot J, Helms M, Mark D, Blumenthal J, Califf R, Haney T, et al. Depression and long-term mortality risk in patients with coronary artery disease. Am J Cardiol. 1996;78:613-7.

31. Koch C, Khandwala F, Nussmeier N, Blackstone E. Gender profiling in coronary artery bypass grafting. $J$ Thorac Cardiovasc Surg. 2003; 126:2044-51.

32. Hedback B, Perk J, Hornblad M, Ohlsson U. Cardiac rehabilitation after coronary artery bypass surgery: 10 year results on mortality, morbidity and readmissions to hospital. J Cardiovasc Risk. 2001;8: 153-8.

33. Froelicher V, Jensen D, Sullivan M. A randomized trial of the effects of exercise training after coronary artery bypass surgery. Arch Intern Med. 1985;145:689-92.

34. Goble AJ, Hare DL, Macdonald PS, Oliver RG, Reid MA, Worcester MC. Effect of early programs of high and low intensity exercise on physical performance after transmural acute myocardial infarction. $\mathrm{Br}$ Heart J. 1991;65:126-31.

35. Wright D, Williams S, Riely R, Marshall P, Tan L. Is early, low level, short term exercise cardiac rehabilitation following coronary bypass surgery beneficial? A randomised controlled trial. Heart. 2002;88: 83-4.

36. Dylewicz P, Bienkowska S, Szczesniak L, Rychlewski T, Przywarska I, Wild M, et al. Beneficial effect of short-term endurance training on glucose metabolism during rehabilitation after coronary bypass surgery. Chest. 2000;117:47-51.

37. Ades P, Waldmann M, Polk D, Coflesky J. Referral patterns and exercise response in the rehabilitation of female coronary patients aged greater than or equal to 62 years. Am J Cardiol. 1992;69:1422-5.

38. Thomas R, Miller N, Lamendola C, Berra K, Hedbacvk B, Durstine J, et al. National survey on gender differences in cardiac rehabilitation programs. Patient characteristics and enrollment patterns. J Cardiopulm Rehabil. 1996;16:402-12.

See appendixes on pages 294 and 295. 
Appendix 1. Baseline continuous variables according to gender

\begin{tabular}{|c|c|c|c|c|c|}
\hline \multirow[b]{3}{*}{ Characteristic } & \multicolumn{4}{|c|}{ All patients } & \multirow[b]{3}{*}{$\begin{array}{c}\text { Student } t \text { test, } \\
P \text { value }\end{array}$} \\
\hline & \multicolumn{2}{|c|}{ Male sex } & \multicolumn{2}{|c|}{ Female sex } & \\
\hline & n & $\begin{array}{l}\text { Mean } \\
( \pm S D)\end{array}$ & n & $\begin{array}{l}\text { Mean } \\
( \pm S D)\end{array}$ & \\
\hline \multicolumn{6}{|l|}{ Demographics } \\
\hline Age at the time of the operation (y) & 1342 & $65 \pm 10$ & 485 & $68 \pm 10$ & $<.01$ \\
\hline Weight (kg) & 1342 & $88 \pm 16$ & 484 & $73 \pm 15$ & $<.01$ \\
\hline Body surface area $\left(\mathrm{m}^{2}\right)$ & 1342 & $2.0 \pm 0.2$ & 484 & $1.8 \pm 0.2$ & $<.01$ \\
\hline Months to follow-up & 1342 & $8.0 \pm 1.1$ & 483 & $8.0 \pm 1.0$ & .89 \\
\hline \multicolumn{6}{|l|}{ Preoperative laboratory values } \\
\hline Hematocrit $(\%)$ & 1342 & $41 \pm 4.3$ & 485 & $37 \pm 4.3$ & $<.01$ \\
\hline Bilirubin (mg/dL) & 1253 & $0.8 \pm 0.3$ & 459 & $0.6 \pm 0.3$ & $<.01$ \\
\hline Albumin $(\mathrm{g} / \mathrm{dL})$ & 1253 & $4.1 \pm 0.5$ & 461 & $3.9 \pm 0.5$ & $<.01$ \\
\hline $\mathrm{BUN}(\mathrm{mg} / \mathrm{dL})$ & 1342 & $19 \pm 8.0$ & 485 & $20 \pm 12$ & .13 \\
\hline Serum creatinine $(\mathrm{mg} / \mathrm{dL})$ & 1342 & $1.1 \pm 0.6$ & 485 & $1.1 \pm 1.0$ & .52 \\
\hline Aortic crossclamp time (min) & 1342 & $77.6 \pm 31.4$ & 485 & $68.4 \pm 30.8$ & $<.01$ \\
\hline
\end{tabular}

BUN, Blood urea nitrogen. 


\begin{tabular}{|c|c|c|c|c|c|}
\hline \multirow[b]{3}{*}{ Characteristic } & \multicolumn{4}{|c|}{ All patients } & \multirow[b]{3}{*}{$\chi^{2}, P$ value } \\
\hline & \multicolumn{2}{|c|}{ Male } & \multicolumn{2}{|c|}{ Female } & \\
\hline & n & $\%$ & n & $\%$ & \\
\hline \multicolumn{6}{|l|}{ Coronary-valvular pathology } \\
\hline Aortic valve regurgitation & 50 & 3.7 & 26 & 5.4 & .12 \\
\hline Mitral valve regurgitation & 156 & 12 & 73 & 15 & .049 \\
\hline Aortic valve stenosis & 13 & 0.07 & 8 & 1.7 & .23 \\
\hline Any circumflex disease & 1194 & 89 & 397 & 82 & $<.01$ \\
\hline Any left main disease & 617 & 46 & 204 & 42 & .15 \\
\hline Any LAD disease & 1283 & 96 & 461 & 95 & .60 \\
\hline Any RCA disease & 1222 & 91 & 425 & 88 & .028 \\
\hline \multicolumn{6}{|l|}{ Cardiac comorbidity } \\
\hline Pulmonary hypertension & 8 & 0.6 & 8 & 1.7 & $.05^{*}$ \\
\hline Hypertension & 900 & 67 & 371 & 77 & $<.01$ \\
\hline Heart failure & 193 & 14 & 109 & 23 & $<.01$ \\
\hline Coronary reoperation & 333 & 25 & 64 & 13 & $<.01$ \\
\hline \multicolumn{6}{|l|}{ Noncardiac morbidity } \\
\hline Chronic obstructive pulmonary disease & 85 & 6.3 & 34 & 7.0 & .60 \\
\hline Smoking & 958 & 72 & 208 & 43 & $<.01$ \\
\hline Diabetes & 425 & 32 & 198 & 41 & $<.01$ \\
\hline Dialysis & 7 & 0.5 & 11 & 2.3 & $<.01^{*}$ \\
\hline Stroke & 81 & 6.0 & 37 & 7.6 & .22 \\
\hline Vascular disease & 163 & 12 & 61 & 13 & .8 \\
\hline Vascular surgery & 51 & 3.8 & 13 & 2.7 & .25 \\
\hline Carotid surgery & 75 & 5.6 & 20 & 4.1 & .21 \\
\hline Carotid disease & 207 & 15 & 97 & 20 & .02 \\
\hline \multicolumn{6}{|l|}{ Symptoms } \\
\hline Emergency surgery & 46 & 3.4 & 13 & 2.7 & .43 \\
\hline Preoperative IABP & 40 & 3.0 & 13 & 2.7 & .74 \\
\hline \multicolumn{6}{|l|}{ Ventricular function } \\
\hline Myocardial infarction & 708 & 53 & 259 & 53 & .81 \\
\hline Abnormal left ventricular function & & & & & .65 \\
\hline Normal & 638 & 48 & 237 & 49 & \\
\hline Mild & 283 & 21 & 99 & 20 & \\
\hline Mild-moderate & 43 & 3.2 & 21 & 4.3 & \\
\hline Moderate & 143 & 11 & 56 & 12 & \\
\hline Moderate-severe & 77 & 5.7 & 25 & 5.2 & \\
\hline Severe & 158 & 12 & 47 & 9.7 & \\
\hline \multicolumn{6}{|l|}{ Operative factors } \\
\hline Left internal thoracic graft & 1045 & 77.9 & 384 & 79.2 & .55 \\
\hline Right internal thoracic graft & 272 & 20.3 & 60 & 12.4 & $<.01$ \\
\hline Intra-aortic balloon pump & 79 & 5.9 & 23 & 4.7 & .35 \\
\hline Return to operating room & 77 & 5.7 & 27 & 5.6 & .89 \\
\hline
\end{tabular}

$L A D$, Left anterior descending coronary artery; $R C A$, right coronary artery; $I A B P$, intra-aortic balloon pump.

*Fisher exact test.

Appendix 3. Postoperative events according to gender

\begin{tabular}{lrrrrrr}
\hline & \multicolumn{4}{c}{ All patients } & \\
\cline { 2 - 3 } & \multicolumn{3}{c}{ Male } & & Female & \\
\cline { 2 - 3 } Characteristic & $\mathbf{n}$ & $\%$ & $\mathbf{n}$ & $\%$ & \multirow{2}{*}{$\boldsymbol{\chi}^{2}, \boldsymbol{P}$ value } \\
\hline Intubation morbidity & 40 & 3.0 & 22 & 4.5 & .10 \\
Cardiac morbidity & 9 & 0.7 & 7 & 1.4 & $.15^{*}$ \\
Neurologic morbidity & 10 & 0.8 & 7 & 1.4 & $.17^{*}$ \\
Serious infection morbidity & 23 & 1.7 & 3 & 0.6 & .08 \\
Gl-hepatic morbidity & 14 & 1.0 & 1 & 0.2 & $.14^{*}$ \\
\hline
\end{tabular}

GI, Gastrointestinal.

${ }^{*}$ Fisher exact test. 